\title{
ASPECTOS HISTÓRICOS E A SITUAÇÃO ATUAL DAS COLEÇÕES DE RÉPTEIS E ANFÍBIOS DO MUSEU INTEGRADO DE RORAIMA
}

\author{
Sebastião Pereira do NASCIMENTO ${ }^{1}$
}

\begin{abstract}
RESUMO: Foi traçado o histórico e comentada a presente condição da coleção de herpetofauna (répteis e anfíbios) do Museu Integrado de Roraima (MIRR). Atualmente, esta coleção possui 838 espécimes catalogados, sendo 44,2\% de anfíbios, 26,1\% de lagartos (incluindo os Amphisbaenidae), 22,7\% de serpentes, $5,2 \%$ de quelônios e $0,8 \%$ de crocodilianos. Desses grupos, a maioria das espécies são bem representativas da herpetofauna local.
\end{abstract}

Palavras-chave: Coleção, Herpetofauna, Roraima.

Historical aspects and current situation of the reptiles and amphibians collection.

ABSTRACT: It was realized a historical review and commented the present condition of the herpetofauna collection (reptiles and amphibians) of the Integrated Museum of Roraima (MIRR). This collection possesses 838 classified specimens, being 44.2\% of amphibians, 26.1\% of lizards (including Amphisbaenid), $22.7 \%$ serpents, $5.2 \%$ of turtle and $0.8 \%$ of crocodilia. The most of these species groups are representative of the local herpetofauna.

Key-Words: Collection, Herpetofauna, Roraima.

INTRODUÇÃO

Considerando os estudos ecológicos que utilizam diferentes grupos de animais e plantas para verificação de hipóteses e o crescente grau de destruição do meio ambiente, que influencia no desaparecimento de muitos organismos, é importante destacar o papel das coleções zoológicas regionais como uma entidade de reserva do patrimônio científico. Tais coleções, além de facilitar a compreensão da composição faunística de uma determinada área ou região, permitem ao pesquisador formular e executar com segurança ativida-

${ }^{1}$ Setor de Zoologia, Museu Integrado de Roraima - MIRR

Av. Brigadeiro Eduardo Gomes s/n Parque Anauá 69305-010 Boa Vista, Roraima, Brasil

Bol. Mus. Integrado de Roraima, Boa Vista 5:19-24. 1999 
des de cunho científico, voltadas a seu campo de interesse. Com isso, é possível ampliar o conjunto de informações científicas que resultarão em benefícios à humanidade. $E$ importante frisar, no entanto, que estas informações são apenas passiveis de posterior verificação se, em suas publicações, os pesquisadores indicarem a deposição dos espécimes-testemunho de seus estudos numa coleção institucional (McAlpine,1986). Esta prática permite a verificação da aplicação correta de um nome científico no qual os resultados da pesquisa estão baseados, dando aos pesquisadores do presente e do futuro a oportunidade de confirmar ou corrigir tal identificação (Happ-Py-Daniel \& Leao,1991). Por exemplo, uma boa coleção zoológica é aquela que tem um amplo arsenal de informações referentes aos lotes de material depositados. Porém, iniciar e manter um acervo referencial deste tipo não é tarefa fácil, mas é de extremo valor, pois é parte integrante da base do conhecimento científico de qualquer região. O apoio de museus e instituições científicas é imprescindível, pois, sem os mesmos, seria praticamente impossível manter por longo prazo uma atividade desta natureza. Neste sentido, o Museu Integrado de Roraima (MIRR) ${ }^{2}$, único órgão de pesquisa de âmbito do governo estadual, vem ratificando seu compromisso de resguardar parte do patrimônio científico regional. Embora de forma limitada e com dificuldades, ele detém a formação de coleções zoológicas onde, nesses últimos anos, se destacam as de répteis e anfíbios provenientes de várias regiões do Estado de Roraima, situado no extremo norte da Amazônia. Assim, este trabalho tem por objetivo fazer um resgate histórico e prover o leitor de informações gerais sobre o material herpetofaunístico depositado no MIRR desde sua inauguração, em fevereiro de 1985.

\section{HISTÓRICO}

A coleção herpetológica do MIRR tem seus fundamentos na recente história cientifica de Roraima. Baseia-se em três diferentes fases de formação. A primeira fase firmou seus primeiros passos a partir do ano de 1985. Sua criação deve-se inicialmente ao empenho do Dr. Celso Morato de Carvalho - pesquisador do INPA que à época demonstrou interesses em (1) desenvolver pesquisas relacionadas à herpetofauna local e (2) consolidar o Núcleo de Pesquisas do INPA em Roraima (Weigel, 1997). Com isto, houve um grande impulso ao suporte científico dado ao MIRR, por causa da parceria que vinculava $\circ$ INPA a algumas atividades de pesquisas desenvolvidas pelo $\mathrm{Mu}-$ seu. Dessa forma, por sugestão do Dr. Celso Morato, foram elaborados vários projetos dos quais surgiu a proposta para a formação de uma coleção zoológica regional no MIRR. A partir de então, as atividades de coleta começaram a ser

2 Órgão vinculado à Secretaria de Educação, Cultura e Desporto do Governo de Roraima, criado pelo Decreto Territorial no 026/84 (25.07.1984) pelo então Governador Arídio M. Magalhães. Sua inauguração se deu em 13.02.1985. 
Aspectos históricos e situação atual da coleção ...

desenvolvidas em conjunto com a equipe de Zoologia do museu liderada pelo Professor Manuel do Nascimento ${ }^{3}$. Pelo acordo celebrado, a maior parte do material coletado era depositada na coleção regional, outra, era enviada para o Museu de Zoologia da Universidade de São Paulo (MZUSP), o qual era depositário oficial das séries, como parte da contra-partida de orientação científica do Dr. Paulo Emílio Vanzolini ao Dr. Celso Morato.

Até o final de 1985 foram depositados 1.354 exemplares de répteis e anfíbios na coleção do MIRR sendo: 721 serpentes (28 espécies), 259 lagartos (13 espécies) e 374 anfíbios (26 espécies). Segundo observações pessoais do Dr. Celso, o MIRR chegou a possuir à época, em qualidade, a melhor coleção de serpentes da região setentrional do Brasil, sendo superado somente pelo Museu de Zoologia da USP. Entretanto, a ascensão da coleção do MIRR não pôde ser continuada por absoluta falta de condições de trabalho e espaço físico adequados para deposição do acervo e, principalmente, ajudado por uma crise administrativa no primeiro semestre de 1986, o que motivou o afastamento da equipe de herpetologia do MIRR e seu conseqüente deslocamento para - Centro de Ciências de Roraima (CECIR), órgão pertencente a Secretaria de Educação do Estado que, na época, vinha sendo consolidado. Em função das dificuldades e da falta de pessoal qualificado no museu, o Núcleo do INPA, através do Dr. Celso Morato teve de esta- belecer nova parceria, desta vez, com o CECIR. Todo o material coletado e depositado no MIRR ficou sem pessoal qualificado para garantir sua manutenção e conservação.

Nesta segunda fase (1986), o entusiasmo do CECIR em relação a coleção herpetológica não foi tão expoente. A coleção só foi realmente efetivada a partir de 1987 quando este autor foi designado bolsista da CAPES (Coordenadoria de Aperfeiçoamento de Pessoal de Nível Superior) e indicado responsável pela coleção zoológica de referência, de caráter didático, que estava iniciando no CECIR. Todo o apoio e colaboração técnica continuaram sendo prestados pelo INPA, através do Dr. Celso que vinculou um dos projetos da parceria com o Governo de Roraima (levantamento da herpetofauna de Roraima), com vistas a auxiliar a formação desta nova coleção zoológica. Embora esta coleção tivesse um perfil mais didático, as coleções de répteis e anfíbios possuíam o padrão técnico-científico equivalente à coleção iniciada no MIRR. Na prática, isto significava uma continuidade daquela coleção, e se calcava no material coletado pelo projeto de levantamento da herpetofauna, entre 1987-89.

A coleção do CECIR foi praticamente desativada em 1990, quando houve paralisação do apoio da CAPES ao projeto e, conseqüentemente, o afastamento da equipe que prestava serviço à coleção. Com isto, um número expressivo de exemplares da herpetofauna regional ficou sem manutenção e conserva3 Zoólogo, ex-Diretor do Museu Integrado de Roraima, falecido em 1993. 
Ção adequada estando, hoje, em avançada fase de deterioração.

A terceira fase e atual tentativa de se reorganizar uma coleção herpetológica está voltada novamente ao MIRR. A reativação foi a partir de janeiro de 1993, quando este órgão iniciou uma revalorização das atividades de pesquisas herpetológicas através de seu Núcleo de Ciências Naturais. Este, por sua vez, deu ênfase à reestruturação das coleções de répteis e anfíbios. Entretanto, os trabalhos tiveram que iniciar praticamente do "nada", já que do material depositado anteriormente (primeira fase), mais de 90\% estava comprometido devido à falta de manutenção. Mesmo assim, um grande esforço foi feito para recuperar pelo menos parte do material existente. Além disto, houve tentativas de incorporar ao MIRR, a coleção do CECIR. No entanto, todas elas fracassaram; embora ambos os órgãos façam parte da mesma secretaria de estado.

\section{Situação atual da coleção.}

A coleção herpetológica do MIRR é essencialmente uma coleção roraimense. Dos 838 exemplares tombados $95,0 \%$ são procedentes do estado de Roraima e o restante $(5,0 \%)$ são procedentes dos Estados do Amazonas, Pará, e países vizinhos como Venezuela e República Cooperativista da Guiana, o que reforça o caráter regional desta coleção. É enfático dizer que todo o acervo catalogado tem procedências confiáveis (espécimes de procedência duvidosa são inseridos em uma coleção didática, para exposições e estudos comparativos com alunos da rede de ensino e acadêmicos da UFRR). Tecnicamente, $O$ material vem sendo depositado em um espaço físico relativamente adequado. Entretanto, com o volume de coletas aumentando, será necessário um espaço físico melhor futuramente.

Os espécimes da coleção do MIRR são representativos de várias regiões do estado de Roraima tanto material coletado, como de doação. É possível dividir os grupos pelas duas grandes macro-paisagens fitofisionômicas existentes em Roraima: áreas abertas e de mata. Os grupos melhor representados são os provenientes das áreas abertas, conhecidas regionalmente como lavrado (ver Vanzolini \& Carvalho, 1991). Do acervo da coleção, a maioria está conservada em via úmida (álcool 70\%), além de diversas peças (peles, carapaças e crânios de grandes répteis) preservadas a seco. Antes deste processo de conservação, todo o material é passado pelo método tradicional de fixação à base de formaldeído $10 \%$.

A grande maioria da coleção $(55,8 \%)$ está composta pelo grupo dos répteis, sendo $22,7 \%$ de serpentes, 26,1\% de lagartos, 5,2\% de quelônios, $0,8 \%$ de crocodilianos. Os anfibios constituem 44,2\% de todo o material tombado. Dentre as serpentes $69,1 \%$ pertencem à família Colubridae, com os seguintes gêneros representados: Liophis $(28,1 \%)$ Leptodeira $(27,4 \%)$, Pseudoboa (14,8\%), Oxibelis (5,1\%), Hidrops (3, 7\%), Leptophis, Chironius, spilotes e Phimophis 
Aspectos históricos e situação atual da coleção ...

(2, 9\%), Erythrolamprus (2, 2\%), Oxirhopus, Dipsas e Drymarchon $(1,4 \%)$, Ligophis, Rhadinae e Tripanurgos $(0,7 \%)$. A familia Boidae, com seus respectivos gêneros: $\operatorname{Boa}(43,4 \%)$, Epicretes $(39,1 \%)$, Eunectes e Corallus $(8,6 \%)$, representa $12.0 \%$ do total das serpentes. O mesmo percentual da família Viperidae $(12,0 \%)$, com dois gêneros representados: Bothrops $(65,2 \%)$ e crotalus $(34,7 \%)$. As famílias Elapidae (com um único Gênero Micrurus) e Leptotyphlopidae (também com um único Gênero Leptotyphlops) representam respectivamente $2.0 \%$ e $4.7 \%$.

Do grupo dos lagartos, as famílias mais destacadas são, em ordem de representatividade: Tropiduridae $(36,5 \%)$ com um único gênero Tropidurus. Gekkonidade $(23,7 \%) \quad$ com três gêneros ; Coleodactylus (51,9\%), Hemidactylus $(40,3 \%)$ e Gonatodes $(7,6 \%)$. A família Teiidae com 21,9\% do total dos lagartos, está representada por seis gêneros, Cnemidophorus (52,0\%), Gymnophthalmus $(20,8 \%)$, Ameiva $(12,5 \%), \quad$ Kentropyx $(6,2 \%)$, Tupinambis e Crocodilurus $(4,1 \%)$. Em seguida vem a família Polycridae com 10,5\%, representada com um único gênero (Anolis); depois, vem a família Iguanidae, com 5,4\% dos lacertílios, representada por três gêneros, Iguana (50,0\%), Uranoscodon $(33,3 \%)$ e Plica $(16,6 \%)$. Por último, se encontram as familias scincidae (1,8\%), Lacertoidae $(0,4 \%)$ e os sauros Amphisbaenidae $(2,7 \%)$, representadas com apenas um único gênero cada (Mabuya, Bachia, Amphisbaena respectivamente) .
Os quelônios, embora não formem um grupo quantitativamente bem representado na coleção, possuem uma grande importância quanto ao nível de sua ecologia e distribuição em Roraima. A família Pelomedusidae, com o gênero Podocnemis, é a melhor representada dentre os quelônios, com um percentual de $68,1 \%$ do total. As famílias Testudinidae $(13,6 \%)$, Emydidae $(4,5 \%)$ e Kinosternidae $(2,2 \%)$, estão representadas também com um único gênero respectivamente, Geochelone, Rinoclemis e Kinosternon. Em destaque também se encontra a familia chelidae $(11,3 \%)$, representada por dois gêneros, Phrynops $(60,0 \%)$ e Chelus $(40,0 \%)$.

Os Crocodylianos constituem apenas $0,8 \%$ do acervo geral da coleção, e estão representados por uma única família (Aligatoridae) e dois gêneros: Caiman $(57,1 \%$ ) e Melanosuchus $(42,8 \%)$.

Do grupo dos anfíbios, 43,3\% pertencem à familia Leptodactylidae, com quatro gêneros: Leptodactylus $(60,9 \%)$, Pseudopaludicola $(31,3)$, Pleurodema $(7,1 \%)$ e Physalaemus $0,5 \%$. A familia Bufonidae com $20,2 \%$, está representada por um único gênero (Bufo). Em seguida está a família Hylidae $(15,3 \%)$ com três gêneros: Hyla $(78,7 \%)$, ololygon $(15,7 \%)$ e Phrynohyas $(5,2 \%)$ e, em seguida, a família Pseudidae $(14,2 \%)$, representada com dois gêneros: Lysapsus $(73,5 \%)$ e Pseudis $(26,4 \%)$. As familias Microhylidae $(4,3 \%) \quad$ e Phyllomedusidae $(0,2 \%)$ são as de menor destaque na coleção, com um único gênero cada: Elachistocleis 
e Phyllomedusa respectivamente.

\section{CONSIDERAÇÕES FINAIS}

Apesar de ter passado por percalços ao longo destes últimos 15 anos, a coleção do MIRR está agora em consolidação dentro de uma programação institucional. Para tanto, ela vem mantendo os padrões técnicos tradicionais de coleta, identificação e conservação indispensáveis a qualquer coleção científica. Além disto, está inaugurando um processo de informatização que disponibilizará, através de um banco de dados, todas as informações constantes nos registros dos exemplares depositados na coleção. Isto oferece inúmeras vantagens aos usuários local e regional, como por exemplo, maior rapidez ao acesso dos dados, qualidade na padronização dos registros, facilidade de intercâmbio com especialista e melhor possibilidade de consulta por curadores de outras coleções.

Embora a coleção necessite de uma boa revisão sistemática, principalmente no tocante aos anfíbios, é importante ressaltar que, no que diz respeito ao seu caráter regional, ela vem cumprindo o seu papel. Ainda que a passos menos longos do que o desejado, ela vem entrando no cenário científico da Amazônia como um potencial de referência à pesquisa em herpetofauna.

\section{REFERÊNCIAS BIBLIOGRÁFICAS}

HAPP-PY-DANIEL, L.H. \& E.L.M. LEÃO. 1991. A coleção de peixe do INPA: Base do conhecimento científico sobre a ictiologia amazônica gerado pelo Instituto Nacional de Pesquisas da Amazônia. In: Val, A.L., Figliuolo,R. \& Feldberg, E.(eds.), Bases Científicas para Estratégias de preservação e Desenvolvimento da Amazônia: Fatos e perspectivas. INPA, Manaus, pp.299-312.

MCALPINE, D.F. 1986. Curators and natural history collections: have we become islands in science? In: Proceedings of the 1985 workshop on care and maintenance of natural history collections. J.Waddington \& D.M.Rudkin (eds.). Life Sciences Miscellaneous Publication. Royal Ontario Museum, Toronto. pp.29-32.

WEIGEL, P. 1997. A importância das bases do INPA no desenvolvimento científico da Amazônia: o caso de Roraima. In: Barbosa, R.I., Ferreira, E \& Castellón, E. (eds.), Homem. Ambiente e Ecologia no Estado de Roraima. INPA, Manaus, pp.217-228.

VANZOLINI, P.E. \& CARVALHO, C.M. 1991. Two sibling and sympatric species of Gymnophthalmus in Roraima, Brasil (Sauria: Teiidae). Papéis Avulsos de Zoologia 37 (12): 173-226. 